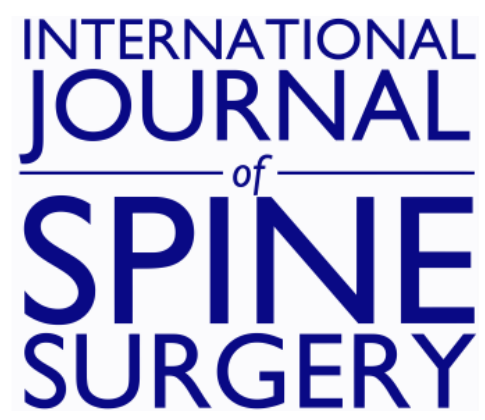

\title{
Clinical and Radiographic Outcomes of Lateral Interbody Fusion for Adjacent Segment Degeneration
}

Siamak Yasmeh, James Bernatz, Eli Garrard, Miranda Bice and Seth K. Williams

Int J Spine Surg 2021, 15 (1) 74-81

doi: https://doi.org/10.14444/8010

http://ijssurgery.com/content/15/1/74

This information is current as of April 26, 2023.

Email Alerts Receive free email-alerts when new articles cite this article. Sign up at:

http://ijssurgery.com/alerts

The International Journal of Spine Surgery

2397 Waterbury Circle, Suite 1,

Aurora, IL 60504, Phone: +1-630-375-1432 


\title{
Clinical and Radiographic Outcomes of Lateral Interbody Fusion for Adjacent Segment Degeneration
}

\author{
SIAMAK YASMEH, MD,${ }^{1} \mathrm{JAMES} \mathrm{BERNATZ,} \mathrm{MD,}{ }^{2}$ ELI GARRARD, MD ${ }^{3}$ MIRANDA BICE, MD,${ }^{2}$ SETH K. \\ WILLIAMS, MD ${ }^{2}$ \\ ${ }^{1}$ Department of Orthopaedic Surgery, Loma Linda University School of Medicine, Loma Linda, California, ${ }^{2}$ Department of Orthopedics and Rehabilitation, \\ University of Wisconsin School of Medicine, Madison, Wisconsin, ${ }^{3}$ Department of Orthopedic Surgery, Emory University School of Medicine, Atlanta, Georgia
}

\begin{abstract}
Study Design: Retrospective cohort study.

Objective: Assessment of outcomes in patients undergoing lateral interbody fusion as part of the surgical treatment of adjacent segment deterioration after previous lumbar spine fusion.

Methods: Adult patients with previous lumbar posterior spinal fusion who presented with adjacent segment degeneration and stenosis refractory to nonoperative treatment and who underwent lateral lumbar interbody fusion were retrospectively analyzed. Clinical and radiographic outcomes were assessed and comparisons made between preoperative baseline and postoperative values.

Results: Thirty-six patients with symptomatic adjacent segment degeneration at 46 motion segments were included. Thirty $(83.3 \%)$ of the 36 patients had complete relief of both preoperative lower extremity pain and back pain at the time of final follow-up. Six (16.7\%) of the 36 patients had persistent pain, though in all 6 cases, the pain was less postoperatively than preoperatively. Oswestry Disability Index scores were improved significantly at final follow-up $(P$ $=.001)$. Compared with preoperative baseline parameters, initial and final postoperative radiographs had an increase in segmental lordosis $(P<.001$ and $P<.001$, respectively), increase in overall lumbar lordosis $(P<.05$ and $P=.094$, respectively), decrease in segmental coronal angulation $(P=.63$ and $P<.01$, respectively), decrease in overall coronal angulation $(P=.063$ and $P=.009$, respectively), and increase in intervertebral height $(P<.001$ and $P<.001$, respectively).
\end{abstract}

Conclusion: Lateral lumbar interbody fusion achieves favorable clinical and radiographic outcomes for the treatment of adjacent segment degeneration after previous lumbar fusion.

Level of Evidence: 4.

Lumbar Spine

Keywords: lateral interbody, antepsoas, lumbar fusion, adjacent segment disease

\section{BACKGROUND}

Adjacent segment degeneration requiring surgical treatment is a common problem after previous lumbar fusion and has been described to occur at a cumulative rate of $16.5 \%$ at 5 years and $36.1 \%$ at 10 years. ${ }^{1-5}$ Several surgical techniques have been described in the literature for adjacent segment degeneration. These include a variety of fixation options including posterolateral spinal fusion with or without instrumentation and with or without interbody fusion, as well as anterior approaches. ${ }^{6-10}$

Lateral interbody fusion is a contemporary fusion option that was first described in 2001 by Ozgur et al. ${ }^{11}$ Proposed advantages of this approach compared with all-posterior techniques include its minimally invasive muscle-splitting dissection, improved biomechanical construct due to the relatively large interbody cage footprint, improved ability to treat focal kyphosis and sagittal balance problems with a direct or indirect anterior longitudinal ligament (ALL) release, indirect neural element decompression by disk height restoration and/or spondylolisthesis reduction, and improved fusion rates. $^{12-16}$

The published literature on lateral interbody fusion for adjacent segment degeneration is relatively limited and is characterized by a small number of patients, inconsistent reporting of outcomes, and/ or a multitude of surgical techniques and fusion constructs. $^{17-21}$

Even in the subset of studies that used supplemental instrumentation to augment the interbody fusion, there is considerable variability with regard to the presence of supplemental instrumentation, 


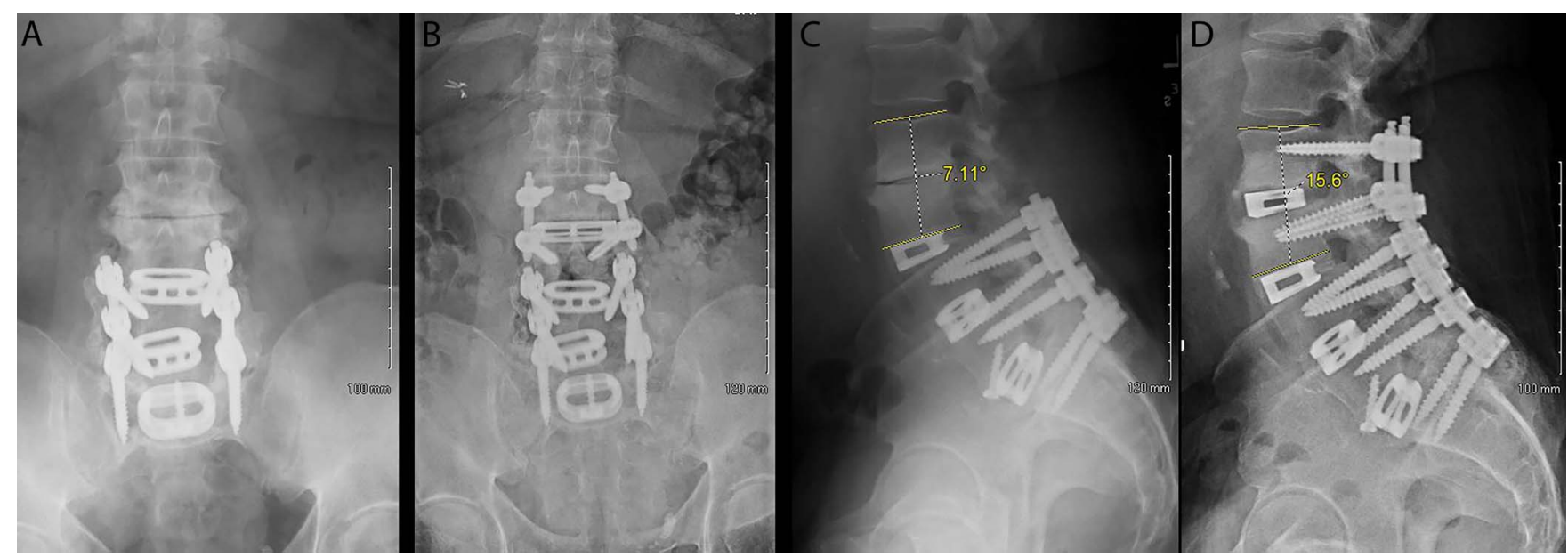

Figure 1. Adjacent segment degeneration 3 years after index lumbar fusion (A, C). Improved lordosis and restoration of intervertebral height after lateral interbody fusion with a $7^{\circ}$ lordotic cage and instrumented posterolateral fusion (C, D).

the type of instrumentation, and whether fixation was unilateral or bilateral in cases of posterior surgery.

The purpose of our study was to report on clinical and radiographic outcomes of lateral lumbar interbody fusion with supplemental lateral or posterior instrumentation for adjacent segment degeneration above a previous lumbar fusion.

\section{METHODS}

\section{Study Population}

This is an institutional review board-approved retrospective review of 36 consecutive adult patients with previous lumbar posterior spinal fusion who presented with adjacent segment degeneration and stenosis at 46 motion segments and whose symptoms were refractory to nonoperative treatment including anti-inflammatory medications, epidural steroid injections, and physical therapy. All patients were treated with lateral interbody fusion by a single fellowship-trained spine surgeon at our tertiary-care medical center between October 2014 and December 2017 (Figure 1). Lateral interbody fusion procedures consisted of a standard anterior to the psoas (ATP) retroperitoneal lateral approach to the lumbar spine and placement of a Titan titanium cage (Titan Spine, Inc, Mequon, WI), Cougar polyether ether ketone (PEEK)/carbon fiber cage (DePuy Synthes Spine, Inc, Raynham, MA), Clydesdale PEEK cage (Medtronic, Inc, Memphis, TN), or Pivox PEEK cage (Medtronic, Inc). Twenty-nine patients had supplementation of the interbody fusion with open or percutaneous posterior instrumentation, whereas 7 had lateral-only constructs consisting of a lateral interbody fusion cage and lateral plating. SmithPeterson osteotomies were performed in 6 cases in which additional restoration of lumbar lordosis (LL) was desired. Direct release of the ALL was performed in 1 case and indirect ALL release performed in 5 cases in which it was felt to be necessary to achieve correction of sagittal plane deformity. Indirect ALL release was performed by sharply cutting approximately $25 \%$ of the ALL under direct visualization, and then using sequentially taller blunt insert-and-rotate intervertebral paddle distractors to place steadily increasing tension on the ALL, ultimately resulting in controlled failure of the ALL to the extent that a lordotic cage of desired height could be inserted. Nine $(25 \%)$ patients underwent a laminectomy for direct neural element decompression in addition to the indirect decompression conferred by the lateral interbody fusion, and 27 (75\%) patients underwent indirect decompression alone.

Patients were followed for a mean of 19.6 (13) months. One patient was lost to follow-up after his first postoperative visit at 1.4 months. There were 19 female and 17 male patients with a mean age of 60.3 (9.7) years (Table 1). Mean body mass index was 29.3 (5.0). Patients underwent surgical treatment of adjacent segment degeneration at a mean of 93.2 (80.9) months after index surgery. The most common level of lateral interbody fusion was L2-3 $(n=20)$ followed by L3-4 $(n=18)$, and L1-2 $(n=8)$. Adjacent segment degeneration developed after a previous single-level fusion in 12 patients, after a 2level fusion in 16 patients, after a 3-level fusion in 7 patients, and after a 4-level fusion in 1 patient. Twenty-seven (75\%) had 1-level, $8(22.2 \%)$ had 2- 
Table 1. Demographics.

\begin{tabular}{lc}
\hline Parameter & Value, $\mathbf{N}=\mathbf{3 6}$ \\
\hline Age, mean (SD), y & $60.3(9.7)$ \\
Gender, \% (n) & \\
$\quad$ Female & $52.8(19)$ \\
$\quad$ Male & $47.2(17)$ \\
Smoking, \% (n) & $9.1(3)$ \\
$\quad$ Smoker & $91.7(33)$ \\
$\quad$ Nonsmoker & \\
Diabetes mellitus, \% (n) & $86.1(31)$ \\
$\quad$ No & $13.9(5)$ \\
$\quad$ Yes & \\
Body mass index, \% (n) & $55.6(20)$ \\
$\quad$ Nonobese $\left(<30 \mathrm{~kg} / \mathrm{m}^{2}\right)$ & $44.4(16)$ \\
Obese $\left(\geq 30 \mathrm{~kg} / \mathrm{m}^{2}\right)$ & \\
Previous number of levels fused, \% (n) & $33.3(12)$ \\
1 & $44.4(16)$ \\
2 & $19.4(7)$ \\
3 & $2.8(1)$ \\
4 &
\end{tabular}

Abbreviation: SD, standard deviation.

level, and $1(2.8 \%)$ had 4-level lateral lumbar surgery.

Biologics in the interbody cage consisted of demineralized bone matrix (DBM) allograft bone (DBX, DePuy Synthes, Zuchwil, Switzerland) alone in 22 patients with Titan cages, DBM and local autogenous rib bone harvested during an L1-2 approach in 4 patients with Titan cages, DBM and bone morphogenetic protein (BMP) (INFUSE rhBMP2, Medtronic, Inc, Minneapolis, $\mathrm{MN}$ ) in 8 patients with DePuy Synthes or Medtronic PEEK cages, and with a combination of DBM, BMP, and local autogenous bone in 2 patients with DePuy Synthes or Medtronic PEEK cages. Autograft was only used for the lateral interbody fusion in cases of L1-2 fusion in which partial 12th rib removal was needed for adequate exposure. BMP was not used in any cases with a Titan titanium cage and was used in all cases performed with a PEEK cage. Posterior instrumentation was placed percutaneously in 7 patients and open in 22 patients. Medical records and radiographs were retrospectively reviewed.

\section{Clinical Outcome}

Clinical assessment included neurologic examination of motor strength and sensation as well as questioning regarding the presence of back and/or lower extremity pain preoperatively, in the immediate postoperative period, and at each follow-up visit at 3 months, 6 months, 1 year, and 2 years postoperatively. Other outcome measures included Oswestry Disability Index (ODI) and Veterans RAND 12 Item Health Survey (VR12). Reoperation was defined as surgery at the level of or the level adjacent to the lateral surgery for any reason. Clinical assessment was performed by the operating surgeon.

\section{Radiographic Outcomes}

Standing lumbar spine radiographs were performed preoperatively, in the immediate postoperative period, and at each follow-up visit at 3 months, 6 months, 1 year, and 2 years postoperatively. Cobb angles for segmental and overall LL as well as for segmental and overall lumbar coronal angulation were measured on lateral and anteriorposterior (AP) projection plain radiographs, respectively. Lordotic angulation was recorded as a negative value, and kyphotic angulation was recorded as a positive value. Intervertebral disc height was calculated for each level treated with a lateral interbody fusion as an average of measurements made at the anterior/posterior and left/right aspects of the disc space on lateral and AP plain radiographs, respectively. Pelvic incidence (PI) was measured on lateral radiographs. Radiographic parameters were recorded and compared for radiographs taken preoperatively, in the immediate postoperative period, and at the most recent follow-up visit.

\section{Statistical Analysis}

Patient characteristics were summarized with mean (standard deviation [SD]), median (range), or N (\%) where applicable. Paired comparison of variables at follow-up compared with baseline were conducted with either paired $t$ tests or McNemar test for pair proportions. All tests were conducted at a .05 significance level, and all analyses were done using $\mathrm{R}$ version 3.3 .

\section{RESULTS \\ Clinical Outcome}

Preoperative evaluation revealed some degree of back pain in all patients and lower extremity radicular pain in $97.2 \%(35 / 36)$ of patients. Thirty $(83.3 \%)$ of the 36 patients had complete relief of both preoperative lower extremity pain and back pain at the time of final follow-up. Six $(16.7 \%)$ of the 36 patients had persistent pain, though in all 6 cases, the pain was less postoperatively than preoperatively. Two of the 6 patients with residual symptoms had back and radicular pain, 3 patients had back pain only, and 1 patient had radicular pain 

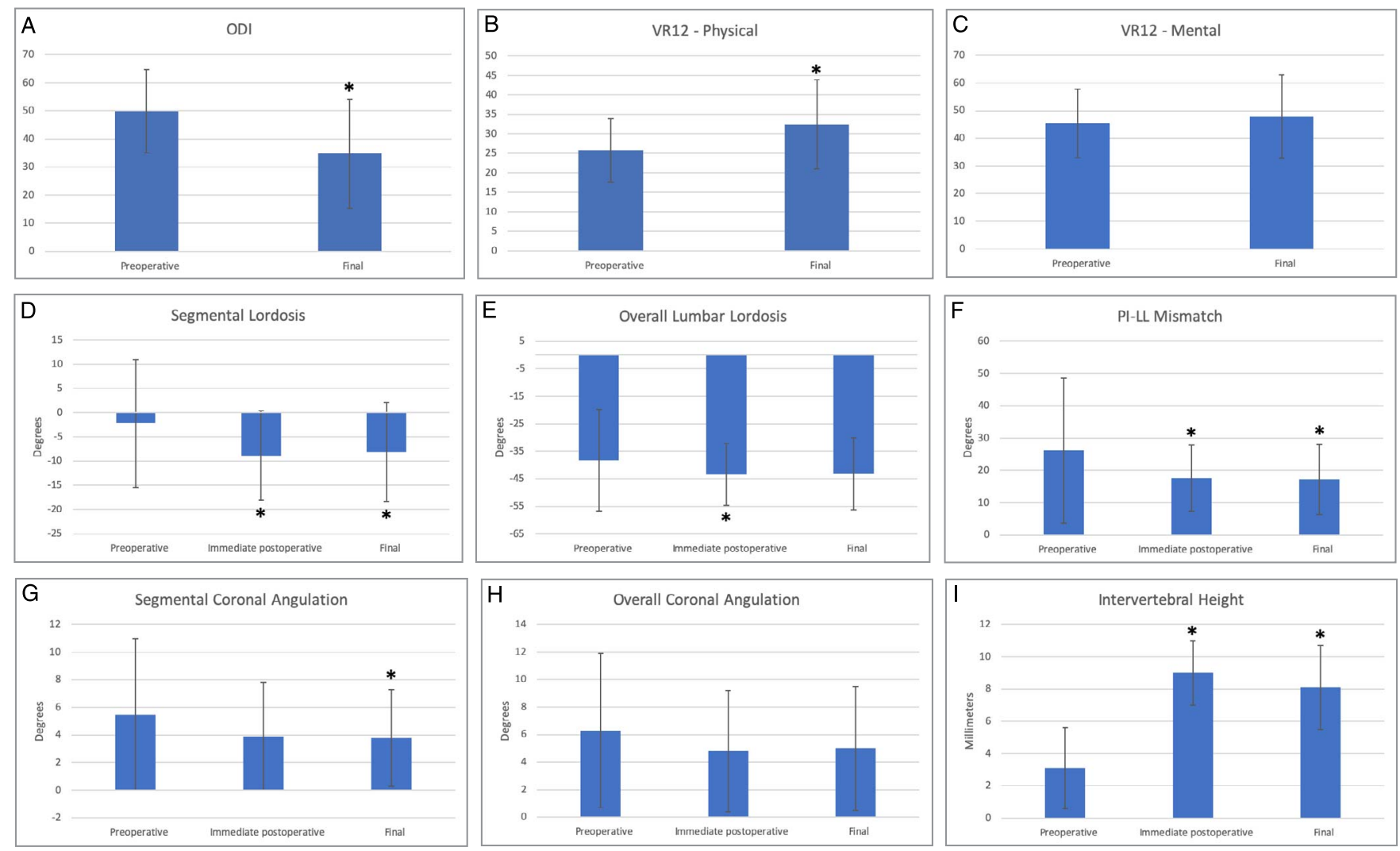

Figure 2. Bar graphs with associated error bars for standard deviation demonstrating clinical $(A-C)$ and radiographic (D-I) outcomes. Statistical significance of changes from preoperative to postoperative intervals are indicated with an asterisk (*).

only. Median (range) time to resolution of back pain was 6 (2-24) weeks and time to resolution of lower extremity radicular pain was also $6(0.5-24)$ weeks. Six $(16.7 \%)$ patients had approach-related hip flexion pain or weakness and/or thigh numbness, of which all but 1 resolved spontaneously. The remaining patient had continued anterior thigh numbness at most recent follow-up at 22 months postoperatively.

The ODI and VR12 data are represented in Figure $2(\mathrm{~A}-\mathrm{C})$ and Table 3. Complete preoperative and postoperative ODI and VR12 data were present for $52.8 \%(19 / 36)$ and $50.0 \%(18 / 36)$ of patients, respectively. ODI was significantly improved $(P=$ .001 ) at a mean follow-up of 18.3 (9.7) months postoperatively. VR12 physical component was significantly improved $(P=.012)$ at final followup. VR12 mental component was similar over time.

\section{Radiographic Outcomes}

Radiographic outcomes are represented in Figure A (D-I) and Table 3. At the immediate postoperative time point, there was a significant increase in segmental lordosis $(P<.001)$ and overall lordosis $(P<.05)$ and a significant decrease in PI-LL mismatch $(P=.013)$. At final radiographic followup at a mean (SD) of 17.2 months (12.8), there was a significant increase in segmental lordosis $(P<.001)$, significant decrease in PI-LL mismatch $(P=.019)$, and a significant improvement in segmental coronal angulation $(P<.01)$. Average intervertebral height was significantly increased at both immediate postoperative $(P<.001)$ and final radiographic follow-up $(P<.001)$ time points.

Table 2. Clinical outcomes.

\begin{tabular}{llcc}
\hline & Mean (SD) & Change (SD) & $\boldsymbol{P}$ Value \\
\hline ODI & & & \\
$\quad$ Preoperative & $49.8(14.8)$ & - & \\
$\quad$ Final & $34.7(19.5)$ & $-15.1(16.8)$ & $.001^{\mathrm{a}}$ \\
VR12, physical & $25.8(8.1)$ & & \\
$\quad$ Preoperative & $32.4(11.4)$ & $6.6(9.9)$ & $.012^{\mathrm{a}}$ \\
$\quad$ Final & & & \\
VR12, mental & $45.4(12.5)$ & - & .480 \\
$\quad$ Preoperative & $47.9(15.1)$ & $2.5(14.5)$ & .480 \\
$\quad$ Final &
\end{tabular}

Abbreviations: ODI, Oswestry Disability Index; SD, standard deviation; VR12, Veterans RAND 12.

${ }^{\text {a }}$ Statistically significant, $P<.05$. 
Table 3. Radiographic outcomes.

\begin{tabular}{|c|c|c|c|}
\hline & Mean (SD) & Change (SD) & $P$ Value \\
\hline \multicolumn{4}{|l|}{ Segmental lordosis, ${ }^{\circ}$} \\
\hline Preoperative & $-2.2(13.2)$ & - & - \\
\hline Immediate postoperative & $-8.8(9.2)$ & $-6.6(9.0)$ & $<0.001^{\mathrm{b}}$ \\
\hline Final & $-8.1(10.2)^{\mathrm{a}}$ & $-5.7(9.9)^{\mathrm{a}}$ & $<0.001^{\mathrm{b}}$ \\
\hline \multicolumn{4}{|l|}{ Overall lordosis, ${ }^{\circ}$} \\
\hline Preoperative & $-38.3(18.5)$ & - & - \\
\hline Immediate postoperative & $-43.4(11.2)$ & $-5.1(13.9)$ & $0.034^{\mathrm{b}}$ \\
\hline Final & $-43.2(13.1)^{\mathrm{a}}$ & $-6.3(14.4)^{\mathrm{a}}$ & 0.092 \\
\hline \multicolumn{4}{|l|}{ PI-LL mismatch, ${ }^{\circ}$} \\
\hline Preoperative & $26.2(22.5)$ & - & - \\
\hline Immediate postoperative & $17.6(10.3)$ & $-8.6(19.6)$ & 0.013 \\
\hline Final & $17.2(10.9)$ & $-8.1(19.5)^{\mathrm{a}}$ & 0.019 \\
\hline \multicolumn{4}{|c|}{ Segmental coronal angulation, ${ }^{\circ}$} \\
\hline Preoperative & $5.5(5.5)$ & - & - \\
\hline Immediate postoperative & $3.9(3.9)$ & $-1.6(5.5)$ & 0.063 \\
\hline Final & $3.8(3.5)$ & $-1.7(4.3)$ & $0.009^{\mathrm{b}}$ \\
\hline \multicolumn{4}{|l|}{ Overall coronal angulation, ${ }^{\circ}$} \\
\hline Preoperative & $6.3(5.6)$ & - & - \\
\hline Immediate postoperative & $4.8(4.4)$ & $-1.5(5.3)$ & 0.089 \\
\hline Final & $5.0(4.5)$ & $-1.3(5.2)$ & 0.144 \\
\hline \multicolumn{4}{|l|}{ Intervertebral height, $\mathrm{mm}$} \\
\hline Preoperative & $3.1(2.5)$ & - & - \\
\hline Immediate postoperative & $9.0(2.0)$ & $5.8(2.0)$ & $<0.001^{\mathrm{b}}$ \\
\hline Final & $8.1(2.6)$ & $5.0(2.4)$ & $<0.001^{\mathrm{b}}$ \\
\hline
\end{tabular}

Abbreviations: LL, lumbar lordosis; PI, pelvic incidence; SD, standard deviation. ${ }^{a}$ Inconsistency in mean and change in both final segmental lordosis and final overall lordosis was due to missing data points from a single patient.

${ }^{\mathrm{b}}$ Statistically significant, $P<.05$.

\section{Complications}

Eight $(22.2 \%)$ of 36 patients underwent reoperation. One patient had a proximal junctional failure through the vertebral body in the form of an L2 vertebral body fracture 6 weeks after surgery. He was found to have osteoporosis and was started on pharmacologic treatment for bone health optimization and subsequently underwent proximal extension of his posterior fusion construct to T10. One patient developed an incisional hernia at the site of the lateral surgery with discomfort in this area. She underwent a laparoscopic hernia repair with resolution of her symptoms. One patient had a clinical picture consistent with a dural tear in the postoperative period and returned to the operating room for exploration. She was found to have a large dural tear at the site of a revision laminectomy, although no dural defect was present during the prior surgery, though the dura was noted to be under tension as a result of disk height restoration and increased lordosis as a result of the interbody cage placement. The dura was unable to be repaired without tension, and so a fascial graft was used successfully without further incident. Two patients underwent partial instrumentation removal for symptomatic posterior instrumentation at the proximal aspect of their fusion construct with resolution of their discomfort. One patient continued to have persistence of lower extremity pain and weakness after a standalone lateral interbody fusion with lateral plating. Repeat magnetic resonance imaging demonstrated that an indirect decompression by the interbody cage was insufficient and there was persistent moderate to severe stenosis at the level of his lateral surgery that was felt to be contributing to his persistent symptoms. He underwent a laminectomy for direct decompression with improvement of his lower extremity pain but no improvement in the weakness that prompted the original surgery. Two patients developed symptomatic proximal adjacent segment disease for which they underwent surgical treatment. There were no pseudarthroses, wound issues, infections, or other complications.

\section{DISCUSSION}

Studies reporting on results of lateral interbody fusion for adjacent segment disease are limited but have shown overall favorable clinical results. Wang et $\mathrm{al}^{17}$ treated 21 patients with adjacent segment stenosis with lateral interbody fusion with anterior vertebral body screws or a lateral plate in 6 cases and standalone constructs without supplemental instrumentation in the remainder. They reported a decrease in visual analog scale (VAS)-reported leg pain from 6.3 to 1.9 points and decrease in back pain from 7.5 to 2.9 points on a 10 -point scale. ${ }^{17}$ Aichmair et $\mathrm{al}^{18}$ reported decreased back and leg pain by 3.8 and 4.1 points, respectively, on a 10point scale in a series of 52 patients who underwent lateral fusion combined with either a lateral plate or posterior instrumentation. Louie et $\mathrm{al}^{19}$ reported a decrease of 5.2 and 1.7 points in back and leg pain, respectively, on a 10-point scale in their series of 25 patients who underwent standalone lateral fusion without plating or pedicle screw instrumentation. In a study of 20 patients with adjacent segment disease treated with lateral interbody fusion and unilateral pedicle screw fixation, Du et $\mathrm{al}^{20}$ reported a 3.4point improvement in VAS scores. Jain et $\mathrm{al}^{22}$ reported a decrease of 1.8 and 2.4 points in VASreported back and leg pain in 17 patients treated with standalone lateral interbody fusion for adjacent segment disease.

Subsidence of the lateral cage is reported as up to $1.7 \mathrm{~mm} \cdot{ }^{17,19,23}$ Wang et al ${ }^{17}$ and Louie et al ${ }^{19}$ both reported an average of $1.7 \mathrm{~mm}$ of interverte- 
bral settling in their respective studies. Marchi et $\mathrm{al}^{23}$ in a study of 98 motion segments treated primarily using standalone lateral interbody without any supplemental instrumentation reported $78 \%$ of cases as having $0 \%$ to $49 \%$ of subsidence and $22 \%$ as having $50 \%$ to $100 \%$ subsidence. Du et $\mathrm{al}^{20}$ found $0 \%$ to $25 \%$ of subsidence in 19 of the 20 patients in their series with unilateral pedicle screw fixation. In our series, there was only $0.9 \mathrm{~mm}$ of intervertebral settling, which compares favorably with the existing literature. Previous studies have shown increased biomechanical strength for lateral interbody fusion augmented with posterior instrumentation compared with lateral interbody fusion alone or with lateral plating. ${ }^{24-26}$ The more frequent use of supplemental posterior instrumentation in our patients compared with cases reported in the literature should be considered when deliberating reasons for the lower rate of subsidence in our study, although unilateral pedicle screw fixation may be a viable alternative to bilateral screws.

Aichmair et $\mathrm{al}^{18}$ reported a $21.2 \%$ overall reoperation rate in their series of patients treated with lateral interbody fusion. The majority of these $(8 / 11)$ were cases of standalone lateral fusion without plate; $25.8 \%(8 / 31)$ of patients with a standalone lateral fusion in their study required reoperation. They concluded that supplemental posterior instrumentation may be necessary to provide additional segmental stability. Similarly, Louie et $\mathrm{al}^{19}$ reported a $12 \%$ reoperation rate for failed standalone lateral lumbar interbody fusion for treatment of adjacent segment degeneration. All patients subsequently underwent placement of posterior instrumentation. In our series, there was a $22.2 \%(8 / 36)$ overall rate of reoperation for any cause related to the surgery. Two patients $(5.6 \%)$ in our series required reoperation for adjacent segment deterioration, and 1 patient $(2.7 \%)$ in our series required reoperation for a vertebral body fracture at the cephalad level of the construct. No mechanical failures occurred in the subset of patients treated with a lateral plate rather than posterior fixation in our series. This suggests that lateral plate fixation may be successful in properly selected patients with adequate bone quality, especially when there is reactive subchondral sclerosis as a result of disk deterioration that may enhance screw purchase. The added stability from posterior instrumentation may decrease subsidence. Revision posterior spinal fu- sion is known to involve elevated risks of dural tear, surgical site infection, wound complications, and other adverse outcomes. ${ }^{27-31}$ However, it is unknown whether the overall rate of reoperation differs between lateral fusion and posterior spinal fusion. In a study comparing standalone lateral interbody fusion without supplemental instrumentation and open laminectomy with instrumented posterolateral fusion in 47 patients with adjacent segment disease, Louie et $\mathrm{al}^{32}$ reported $13.0 \%$ reoperations in the former compared with $20.8 \%$ reoperations in the latter. In contrast, Jain et $\mathrm{al}^{22}$ reported $23.5 \%$ and $18.8 \%$ reoperations in patients undergoing standalone lateral interbody fusion and transforaminal lumbar interbody fusion, respectively, although the difference was not statistically significant.

Our study has several limitations. First, assessment of radiographic outcomes based on radiographs is adequate for determining improvement in LL and coronal angulation but may not be as accurate as computed tomography in determining whether fusion was achieved, though there was no radiographic evidence of pseudoarthrosis. Second, follow-up time was limited to a mean of 19.6 months. This time frame generally allows for detection of persistent or recurrent symptoms and symptomatic pseudarthroses, but limits an accurate assessment of the incidence and rate of onset of additional adjacent segment deterioration. Third, because data collection occurred during the time when functional outcomes scores were beginning to be collected on all patients at our institution, complete functional outcome scores were available for half of our patients, and this may introduce a source of potential bias.

\section{CONCLUSIONS}

This study demonstrates that lateral interbody fusion with supplemental posterior instrumentation is an effective treatment for adjacent segment degeneration after previous posterior lumbar fusion. Supplemental fixation with a lateral plate rather than posterior instrumentation may be appropriate in properly selected patients.

\section{REFERENCES}

1. Ghiselli G, Wang JC, Bhatia NN, Hsu WK, Dawson EG. Adjacent segment degeneration in the lumbar spine. $J$ Bone Joint Surg Am. 2004;86-A(7):1497-1503.

2. Okuda S, Iwasaki M, Miyauchi A, Aono H, Morita M, 
Yamamoto T. Risk factors for adjacent segment degeneration after PLIF. Spine. 2004;29(14):1535-1540.

3. Sears WR, Sergides IG, Kazemi N, Smith M, White GJ, Osburg B. Incidence and prevalence of surgery at segments adjacent to a previous posterior lumbar arthrodesis. Spine J. 2011;11(1):11-20.

4. Lawrence BD, Wang J, Arnold PM, Hermsmeyer J, Norvell DC, Brodke DS. Predicting the risk of adjacent segment pathology after lumbar fusion: a systematic review. Spine. 2012;37(22 suppl):S123-S132.

5. Donnally CJ 3rd, Patel PD, Canseco JA, et al. Current incidence of adjacent segment pathology following lumbar fusion versus motion-preserving procedures: a systematic review and meta-analysis of recent projections. Spine $J$. 2020;20(10):1554-1565.

6. Miwa T, Sakaura H, Yamashita T, Suzuki S, Ohwada T. Surgical outcomes of additional posterior lumbar interbody fusion for adjacent segment disease after single-level posterior lumbar interbody fusion. Eur Spine J. 2013;22(12):2864-2868.

7. Adogwa O, Carr RK, Kudyba K, et al. Revision lumbar surgery in elderly patients with symptomatic pseudarthrosis, adjacent-segment disease, or same-level recurrent stenosis. Part 1. Two-year outcomes and clinical efficacy: clinical article. $J$ Neurosurg Spine. 2013;18(2):139-146.

8. Whitecloud TS 3rd, Davis JM, Olive PM. Operative treatment of the degenerated segment adjacent to a lumbar fusion. Spine. 1994;19(5):531-536.

9. Chou D, Dekutoski M, Hermsmeyer J, Norvell DC. The treatment of lumbar adjacent segment pathology after a previous lumbar surgery: a systematic review. Spine. 2012;37(22 suppl):S180-S188.

10. Phillips FM, Carlson GD, Bohlman HH, Hughes SS. Results of surgery for spinal stenosis adjacent to previous lumbar fusion. J Spinal Disord. 2000;13(5):432-437.

11. Ozgur BM, Aryan HE, Pimenta L, Taylor WR. Extreme lateral interbody fusion (XLIF): a novel surgical technique for anterior lumbar interbody fusion. Spine J. 2006;6(4):435-443.

12. Kepler CK, Sharma AK, Huang RC, et al. Indirect foraminal decompression after lateral transpsoas interbody fusion. J Neurosurg Spine. 2012;16(4):329-333.

13. Chioffe M, McCarthy M, Swiatek PR, et al. Biomechanical analysis of stand-alone lateral lumbar interbody fusion for lumbar adjacent segment disease. Cureus. 2019;11(11):e6208.

14. Youssef JA, McAfee PC, Patty CA, et al. Minimally invasive surgery: lateral approach interbody fusion: results and review. Spine. 2010;35(26 suppl):S302-S311.

15. Kotwal S, Kawaguchi S, Lebl D, et al. Minimally invasive lateral lumbar interbody fusion: clinical and radiographic outcome at a minimum 2-year follow-up. J Spinal Disord Tech. 2015;28(4):119-125.

16. Pimenta L, Turner AW, Dooley ZA, Parikh RD, Peterson MD. Biomechanics of lateral interbody spacers: going wider for going stiffer. ScientificWorldJournal. 2012;2012:381814.

17. Wang MY, Vasudevan R, Mindea SA. Minimally invasive lateral interbody fusion for the treatment of rostral adjacent-segment lumbar degenerative stenosis without supplemental pedicle screw fixation. $J$ Neurosurg Spine. 2014;21(6):861-866.

18. Aichmair A, Alimi M, Hughes AP, et al. Single-level lateral lumbar interbody fusion for the treatment of adjacent segment disease: a retrospective two-center study. Spine. 2017;42(9):E515-E522.

19. Louie PK, Varthi AG, Narain AS, et al. Stand-alone lateral lumbar interbody fusion for the treatment of symptomatic adjacent segment degeneration following previous lumbar fusion. Spine J. 2018;18(11):2025-2032.

20. Du JY, Kiely PD, Al Maaieh M, Aichmair A, Huang RC. Lateral lumbar interbody fusion with unilateral pedicle screw fixation for the treatment of adjacent segment disease: a preliminary report. J Spine Surg. 2017;3(3):330-337.

21. Choi YH, Kwon SW, Moon JH, et al. Lateral lumbar interbody fusion and in situ screw fixation for rostral adjacent segment stenosis of the lumbar spine. J Korean Neurosurg Soc. 2017;60(6):755-762.

22. Jain D, Verma K, Mulvihill J, et al. Comparison of stand-alone, transpsoas lateral interbody fusion at L3-4 and cranial vs transforaminal interbody fusion at L3-4 and L4-5 for the treatment of lumbar adjacent segment disease. Int $J$ Spine Surg. 2018;12(4):469-474.

23. Marchi L, Abdala N, Oliveira L, Amaral R, Coutinho E, Pimenta L. Radiographic and clinical evaluation of cage subsidence after stand-alone lateral interbody fusion. $J$ Neurosurg Spine. 2013;19(1):110-118.

24. Metzger MF, Robinson ST, Maldonado RC, Rawlinson J, Liu J, Acosta FL. Biomechanical analysis of lateral interbody fusion strategies for adjacent segment degeneration in the lumbar spine. Spine J. 2017;17(7):1004-1011.

25. Fogel GR, Parikh RD, Ryu SI, Turner AW. Biomechanics of lateral lumbar interbody fusion constructs with lateral and posterior plate fixation: laboratory investigation. $J$ Neurosurg Spine. 2014;20(3):291-297.

26. Laws CJ, Coughlin DG, Lotz JC, Serhan HA, Hu SS. Direct lateral approach to lumbar fusion is a biomechanically equivalent alternative to the anterior approach: an in vitro study. Spine. 2012;37(10):819-825.

27. Khan IS, Sonig A, Thakur JD, Bollam P, Nanda A. Perioperative complications in patients undergoing open transforaminal lumbar interbody fusion as a revision surgery. $J$ Neurosurg Spine. 2013;18(3):260-264.

28. Smorgick Y, Baker KC, Bachison CC, Herkowitz HN, Montgomery DM, Fischgrund JS. Hidden blood loss during posterior spine fusion surgery. Spine J. 2013;13(8):877-881.

29. Basques BA, Ibe I, Samuel AM, et al. Predicting postoperative morbidity and readmission for revision posterior lumbar fusion. Clin Spine Surg. 2017;30(6):E770-E775.

30. Wang JC, Bohlman HH, Riew KD. Dural tears secondary to operations on the lumbar spine. Management and results after a two-year-minimum follow-up of eighty-eight patients. J Bone Joint Surg Am. 1998;80(12):1728-1732.

31. Eichholz KM, Ryken TC. Complications of revision spinal surgery. Neurosurg Focus. 2003;15(3):E1.

32. Louie PK, Haws BE, Khan JM, et al. Comparison of stand-alone lateral lumbar interbody fusion versus open laminectomy and posterolateral instrumented fusion in the treatment of adjacent segment disease following previous lumbar fusion surgery. Spine. 2019;44(24):E1461-E1469.

Disclosures and COI: The authors received no funding for this study. SKW has consulting agreements with DePuy Synthes, Stryker, Medtronic, SeaSpine, Terumo, and Royal Biologics. The 
remaining authors report no conflicts of interest. This study was approved by the Institutional Review Board at the University of Wisconsin.

Corresponding Author: Siamak Yasmeh, MD, Department of Orthopaedic Surgery, Loma Linda University School of Medicine, 11406 Loma Linda Dr, Suite 226, Loma Linda, CA 92354;
Phone: (909)-558-6444; Email: syasmeh@gmail. com.

Published 26 February 2021

This manuscript is generously published free of charge by ISASS, the International Society for the Advancement of Spine Surgery. Copyright (C) 2021 ISASS. To see more or order reprints or permissions, see http://ijssurgery.com. 